\title{
Atmospheric Cold Plasma Inactivation of Salmonella and Escherichia coli on the Surface of Golden Delicious Apples
}

\author{
Agnes Kilonzo-Nthenge ${ }^{1}$, Siqin Liu ${ }^{2}$, Sudheer Yannam ${ }^{2}$ and Ankit Patras ${ }^{2 *}$ \\ ${ }^{1}$ Department of Human Sciences, Tennessee State University, Nashville, TN, United States, ${ }^{2}$ Department of Agricultural and \\ Environmental Sciences, College of Agriculture, Tennessee State University, Nashville, TN, United States
}

The contamination of fruits with human pathogens is a reoccurring concern in the fresh produce industry. Atmospheric cold plasma (ACP) is a potential alternate to customary approaches for non-thermal decontamination of foods. In this study, the efficacy of a dielectric barrier discharge ACP system against Salmonella (Salmonella Typhimurium, ATCC 13311; Salmonella Choleraesuis, ATCC 10708) and Escherichia coli (ATCC 25922, ATCC 11775) was explored. For each bacteria, a two-strain mixture at $8 \log _{10} \mathrm{CFU} / \mathrm{ml}$ was spot inoculated on the surface of Golden Delicious apples, air dried, and exposed

OPEN ACCESS

Edited by:

Juan Aguirre,

Universidad de Chile, Chile

Reviewed by:

Brendan A. Niemira,

United States Department of

Agriculture, United States

Dana Ziuzina,

Dublin Institute of Technology, Ireland

*Correspondence: Ankit Patras

apatras@tnstate.edu

Specialty section:

This article was submitted to

Food Microbiology,

a section of the journal

Frontiers in Nutrition

Received: 06 September 2018 Accepted: 19 November 2018 Published: 11 December 2018

Citation:

Kilonzo-Nthenge A, Liu S, Yannam S and Patras A (2018) Atmospheric

Cold Plasma Inactivation of

Salmonella and Escherichia coli on the

Surface of Golden Delicious Apples.

Front. Nutr. 5:120

do: 10.3389/fnut.2018.00120 to ACP at a fixed distance of $35 \mathrm{~mm}$, input power of $200 \mathrm{~W}$ for $30,60,120,180$, and $240 \mathrm{~s}$. Bacterial inactivation was achieved in all treatment times with highest reduction of $5.3 \log _{10} \mathrm{CFU} / \mathrm{cm}^{2}$ for Salmonella and $5.5 \log _{10} \mathrm{CFU} / \mathrm{cm}^{2}$ for E. coli. Our results showed that reductions were interrelated to exposure time and ranged from 1.3 to 5.3 and 0.6 to $5.5 \log _{10} \mathrm{CFU} / \mathrm{cm}^{2}$ for Salmonella and E. coli, respectively. Salmonella and E. coli significantly decreased (>5.0 log) at 180 and $240 \mathrm{~s}$ as compared to 30,60 , and $120 \mathrm{~s}$ exposure. Microbial inactivation data was modeled by using Weibull distribution. These findings demonstrate the potential of ACP as a postharvest technology to effectively reduce pathogens on apples, with reference to Salmonella and $E$. coli.

Keywords: atmospheric cold plasma, Salmonella, Escherichia coli, apples, modeling

\section{INTRODUCTION}

Consumer demand for nutritious, safe, and minimally treated foods has stimulated the increased consumption of fresh produce (1). Several studies reveal that consuming more fruits and vegetables result to a more prolific and healthier lifestyle $(2,3)$. However, the number of foodborne illness outbreaks linked to fresh produce has elevated in the recent years. Between November 2010 and November 2012, 5191 individuals were infected with foodborne pathogens from fresh produce products and as a consequence 95 people died in European countries, USA, Canada, and Japan $(4,5)$. According to Painter et al. (6), 46\% of foodborne illnesses are associated with fresh produce. Fresh produce is recognized as a highly potential vehicle for foodborne outbreaks and therefore, a major concern to the food industry, regulatory agencies, and consumers $(7,8)$. The United States and European Union have reported a total of 377 and 198 produce-associated outbreaks from year 2004 to 2012. For the United States, the absolute number of outbreaks due to fresh produce ranged from 23 to 60 per year. There were substantial increases in 2006 (57 outbreaks), 2008 (51 outbreaks), and 2011 (60 outbreaks) $(9,10)$. For the European Union, the number of outbreaks 
oscillated between 10 and 42, highlighting increases in 2006 (29 outbreaks), 2009 (34 outbreaks), and 2010 (44 outbreaks) (11). The number of produce-associated outbreaks remains relatively high and represents a major health and financial issue $(11,12)$.

Consumer's demand for safe, high quality and wholesome food has contributed to the development of novel nonthermal technologies (13). The preservation of food quality is of paramount importance, and practice application must be effective at destroying microorganisms while not causing undesirable alterations in food quality (7). Atmospheric cold plasma (ACP) is a fairly new technology being applied for non-thermal decontamination of foods. This method promotes a proficient inactivation of diverse microorganisms including spores, viruses, yeasts, and fungi including biofilms (14-23).

Plasma involves very energetic species including photons, electrons, positive and negative ions, free radicals and excited or non-excited molecules and atoms, which in combination inactivate microorganisms (24-26). Cold atmospheric plasma, grounded on ionized gases generated at room temperature and atmospheric pressure presents the opportunity of treating the surfaces of fresh produce tissues (27-29). Various types of plasma generating sources are currently available. It includes glow-discharge, radio-frequency discharge, corona discharge, dielectric barrier discharge, atmospheric pressure plasma jet, micro-hollow, gliding arc discharge have been used for food processing applications, generating plasmas by using noble gases is more beneficial as it prevents the oxidative degradation of vitamins and other nutrients on exposure to oxygen. The most economical operations in food systems employ atmospheric air $(14,30)$ which is relatively cheaper.

Vegetative cells such as E.coli O157:H7 and Salmonella are often associated with fresh produce, hence remains to be a threat to the public health $(2,31)$. New technologies such as gas plasma are needed to inactivate pathogens and prevent cross-contamination. Extensive research on the use of plasmas at atmospheric pressure using air as a carrier gas to inactivate microorganisms is a relatively recent phenomenon. Atmospheric pressure cold plasma is an emerging low temperature technology with high antimicrobial efficacy. Gas plasma technique is claimed to be a "rapid, waterless, zero-contact, chemical-free" tool for pathogen removal from food contact surfaces $(14,20)$.

Several authors reported non-thermal atmospheric plasma treatments for decontamination of many food samples including vegetables, meat and meat products, milk and dairy products, fruit juice (32-34). This study fills that knowledge gap and provides inactivation data on a range of vegetative cells. Not much information on the effect of plasma using air as a carrier gas on fruits is available. Therefore, using purified air as a carrier gas for the plasma generation is the novelty of this research study. The main objective of this study was to evaluate the efficacy of atmospheric cold plasma in reducing Salmonella and Escherichia coli on the surface of Golden Delicious apples. A further aim was to evaluate the kinetic models for the inactivation of Salmonella and Escherichia coli on apples.

\section{MATERIALS AND METHODS}

\section{Bacterial Strain and Inoculation Preparation}

Salmonella enterica subspecies enterica serovars (Typhimurium, Choleraesuis) and Escherichia coli (E. coli ATCC 25922; E. coli ATCC 11775) were used in this study. Isolates were maintained at $-80^{\circ} \mathrm{C}$ in tryptic soy broth (TSB; Becton, Dickinson \& Company [BD], Franklin Lakes, NJ) with 15\% glycerol (Fisher Scientific, Pittsburgh, PA). Culture from each bacterial frozen stock was separately inoculated on tryptone soya agar (TSA) plates and grown overnight at $37^{\circ} \mathrm{C}$ to isolate pure colonies. An isolated colony from each plate was transferred to corresponding 10 TSB tube and incubated with shaking $(250 \mathrm{rpm})$ at $37^{\circ} \mathrm{C}$ to create working stock. Subsequently, bacterial cells from each tube were harvested through centrifugation $\left(4,000 \times \mathrm{g}, 15 \mathrm{~min}, 23^{\circ} \mathrm{C}\right)$ and suspended in $10 \mathrm{ml}$ of $0.1 \%$ peptone water. Approximately, $5 \mathrm{ml}$ of each resuspended Salmonella enterica subspecies enterica serovars (Typhimurium, Choleraesuis) cells were combined to make a $10 \mathrm{ml}$ cocktail (a two-strain cocktail mixture). The same procedure used to make Salmonella cocktail was followed for E. coli cocktail (E. coli ATCC 25922; E. coli ATCC 11775). Separately, $1 \mathrm{ml}$ of each bacterial cocktail was re-suspended in $9 \mathrm{ml} 0.1 \%$ peptone and there after serial dilutions mere performed. Next, $0.1 \mathrm{ml}$ from each cocktail was plated on TSA plates and a final inoculum was determined as approximately 8 $\log _{10} \mathrm{CFU} / \mathrm{ml}$ for both Salmonella and E. coli.

\section{Inoculation of Golden Delicious Apples}

The efficacy of ACP on Salmonella and E. coli was evaluated using apples as the test substrate. Fresh Golden Delicious apples were randomly picked and purchased from local supermarkets and held at $4^{\circ} \mathrm{C} 1$ day before the experiment. Prior to inoculating the apples with Salmonella or E. coli cocktail, each apple was dipped in $70 \%$ ethanol for $10 \mathrm{~s}$, rinsed with distilled sterile water, and allowed to air dry for $1 \mathrm{~h}$ in a safety hood cabinet. For negative control (before inoculation), six apples was analyzed to be certain there was no baseline contamination of Salmonella or E. coli on the apples. The apples were cut in halves and placed cut side down onto sterile petri plates. To facilitate inoculation process, a sharpie was used to denote the area of inoculation $\left(12.6 \mathrm{~cm}^{2}\right)$ on the apple halves (29). Next, $0.1 \mathrm{ml}$ $(100 \mu \mathrm{l})$ aliquots of E.coli or Salmonella cocktail were spot inoculated on the denoted area. The inoculum was deposited in form of droplets on several different sites within the denoted area, to ensure that the inoculum did not flow to the side of the apples. After inoculation, samples were then left to dry for $1 \mathrm{~h}$ in a laminar flow safety cabinet to allow the attachment of bacteria on the surface of apples prior to the ACP treatment (35). Following, inoculated apples were treated by ACP and analyzed for microbial inactivation. Four apples were used for each set of treatment and the entire study was accomplished in triplicates.

\section{Indirect Corona Discharge Set-Up by Atmospheric Cold Plasma Treatment}

To treat the apples with ACP, indirect corona discharge system was used in this study (Figure 1). It consisted of a maximum 
high voltage output of 200 Watts at a frequency of $50 \mathrm{~Hz}$. The Corona T-JET enables an indirect Corona-treatment with very low heat transfer into the surface. The corona discharge was generated inside the head between two electrodes and conveyed onto the surface by an air stream. A corona discharge is a physical phenomenon characterized by a low-current electrical discharge across a gas containing gap at a voltage gradient, which exceeds a certain critical value. Filtered air at a pressure of 4 bar at a constant flow-rate of $17 \mathrm{~L} \mathrm{~min}^{-1}$ was used for the plasma generation. The process parameters considered for the treatment was plasma at a fixed distance of $35 \mathrm{~mm}$. Treatment width was approximately $18 \mathrm{~mm}$ (Figure 1). All samples were subjected to plasma treatment under atmospheric pressure. The plasma working gas was atmospheric air. The samples were treated with plasma at intervals of $30,60,120,180$, and $240 \mathrm{~s}$. A mark was made on the surface to denote the orientation of the apple with respect to the rectangular field of plasma. The chemical characterization of the emission in the 220$450 \mathrm{~nm}$ wavelength range (Figure 1) was carried out by an optic fiber probe placed at about $20 \mathrm{~mm}$ from the discharge and connected to a spectrometer (Ocean optics, HR4000 Series, Florida, USA).

\section{Microbial Analysis}

E. coli and Salmonella contaminated apples (positive control) were processed individually; this was to determine the inoculum levels before ACP treatment. After ACP treatment, the inoculated spot $\left(12.6 \mathrm{~cm}^{2}\right)$ on the apple was sampled using a sterile cotton swab immersed in sterile $0.1 \%$ buffered peptone water. The cotton swab tip was thoroughly vortexed for $30 \mathrm{~s}$ in $10 \mathrm{~mL}$ $0.1 \%(\mathrm{w} / \mathrm{v})$ sterile peptone in conical tube. Subsequently, a $10-$ fold serially dilutions in $0.1 \%$ peptone of the homogenate from each sample was plated on appropriate media. Approximately, $0.1 \mathrm{ml}$ aliquots of an appropriate dilution were surface plated on xylose lysine deoxycholate (XLD, Difco, Sparks, MD) agar and Eosin Methylene Blue Lactose Agar (EMB) for Salmonella and E. coli, respectively. All plates were incubated for $24 \mathrm{~h}$ at $37^{\circ} \mathrm{C}$.

\section{Inactivation Kinetics}

The GInaFiT software tool was used to perform the regression analysis of the microbial inactivation data (36). To describe the survival of $S$. Typhimurium and E. coli, different inactivation models are available in the GInaFiT tool, namely the log-linear, log-linear +shoulder, Weibull, Double Weibull, biphasic and biphasic+ shoulder models (Van Boekel 2). Weibull model fitted the experimental data. Inactivation kinetics parameters related to scale and shape of inactivation curves for the model was calculated. The numerical values for inactivation kinetics parameters, time required to obtain 5-log reduction and other similar parameters were calculated for each model. It is wellknown that microbial activation curves are not often straight lines but have a "shoulder" or "tail" effect; thus, the Weibull distribution model was preferred to fit microbial inactivation

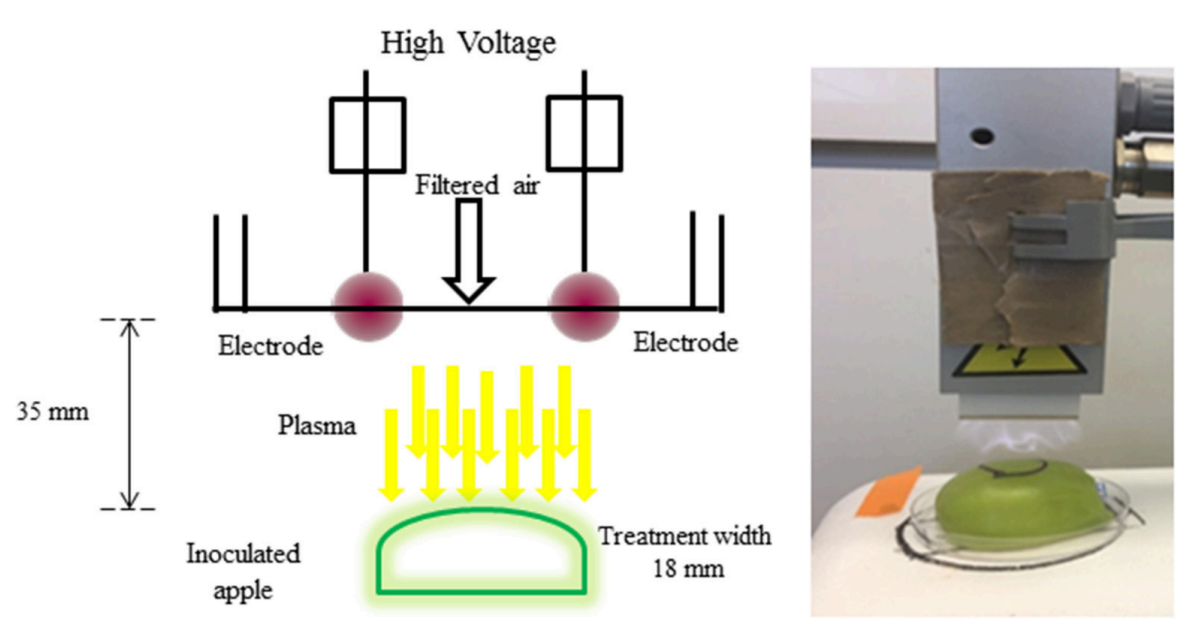

FIGURE 1 | Schematic diagram of atmospheric cold plasma system.

TABLE 1 | Goodness of fit and model parameters.

\begin{tabular}{|c|c|c|c|c|}
\hline Microbe & $R^{2}$ & RMSE & $\delta \pm \mathbf{S E}$ & $P \pm S E$ \\
\hline Salmonella Typhimurium ATCC 13311 & 0.92 & 0.48 & $12.73 \pm 4.78$ & $0.52 \pm 0.06$ \\
\hline Salmonella Choleraesuis ATCC 10708 & 0.94 & 0.53 & $22.02 \pm 5.65$ & $0.80 \pm 0.1$ \\
\hline Escherichia coli ATCC 25922 & 0.96 & 0.38 & $12.26 \pm 2.87$ & $0.59 \pm 0.04$ \\
\hline Escherichia coli ATCC 11775 & 0.99 & 0.17 & $46.70 \pm 2.84$ & $1.20 \pm 0.05$ \\
\hline
\end{tabular}

SE, Standard error; RMSE, Root mean square error. 
data $(36,37)$. The Weibull model has been used in nonthermal treatment studies for modeling purposes. It is primarily based on the hypothesis that the resistance to stress of a population follows a Weibull distribution $(38,39)$.The Weibull model (eqn 1) was used to analyze the data: where $\mathrm{N}_{t}$ is concentration of microorganisms $\left(\mathrm{CFU} / \mathrm{cm}^{2}\right)$ at time, $\mathrm{t}(0,30$, $60,120,180,240 \mathrm{~s}), \mathrm{N}_{0}\left(\mathrm{CFU} / \mathrm{cm}^{2}\right)$ is the initial number of microorganisms, $\delta$ [min] (time for the first decimal reduction) and $\mathrm{p} \mathrm{[-]}$ are parameters related to the scale and shape of the inactivation curve, respectively. The Weibull distribution corresponds to a concave upward survival curve if $p<1$ and

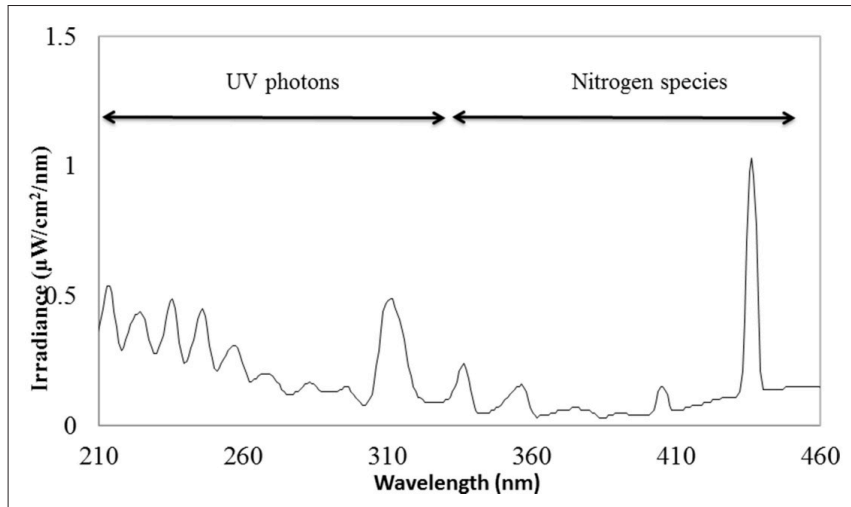

FIGURE 2 | Optical emission spectrum of plasma. concave downward if $p>1$ (40). Inactivation kinetics parameters related to scale and shape of inactivation curves for most suitable models were calculated. The numerical values for inactivation kinetics parameters, time required to obtain 5-log reduction were calculated for the model. The values of $\delta$ and $p$ were used to calculate a desired log reduction. The time required to obtain an $\mathrm{x} \log$ reduction $\left(\mathrm{t}_{\mathrm{xd}}\right)$ was calculated using Equation (2).

$\beta$ describes the shape of the curve $(\beta=1$, straight line; $\beta<1$, concave curve; $\beta>1$, convex curve). The parameter $\alpha$ modifies the slope but it does not affect the shape (40). The Weibull equation can be cast in the decimal logarithmic form.

$$
\begin{array}{r}
\log _{10} N_{\mathrm{t}}=\log _{10}\left(N_{0}\right)-\left(\frac{t}{\delta}\right)^{p} \\
t_{\mathrm{xd}}=\delta \times(x)^{1 / \mathrm{p}}
\end{array}
$$

\section{Statistical Analysis}

Statistical Analysis (SAS Institute, Cary, N.C.) program was used to analyze the data. The surviving population of either E. coli or Salmonella for each treatment was compared with that recovered from its respective inoculated untreated spot (control). This was performed to account for possible day-to-day variation in inoculum strength over the course of the experiments. All plate count data were converted to $\log \mathrm{CFU} / \mathrm{cm}^{2}$ values. A balanced design with three replicates randomized in experimental order were performed for each treatment. The concentrations of $E$. coli and Salmonella spp. (Log CFU/ $\mathrm{cm}^{2}$ ) after plasma treatment
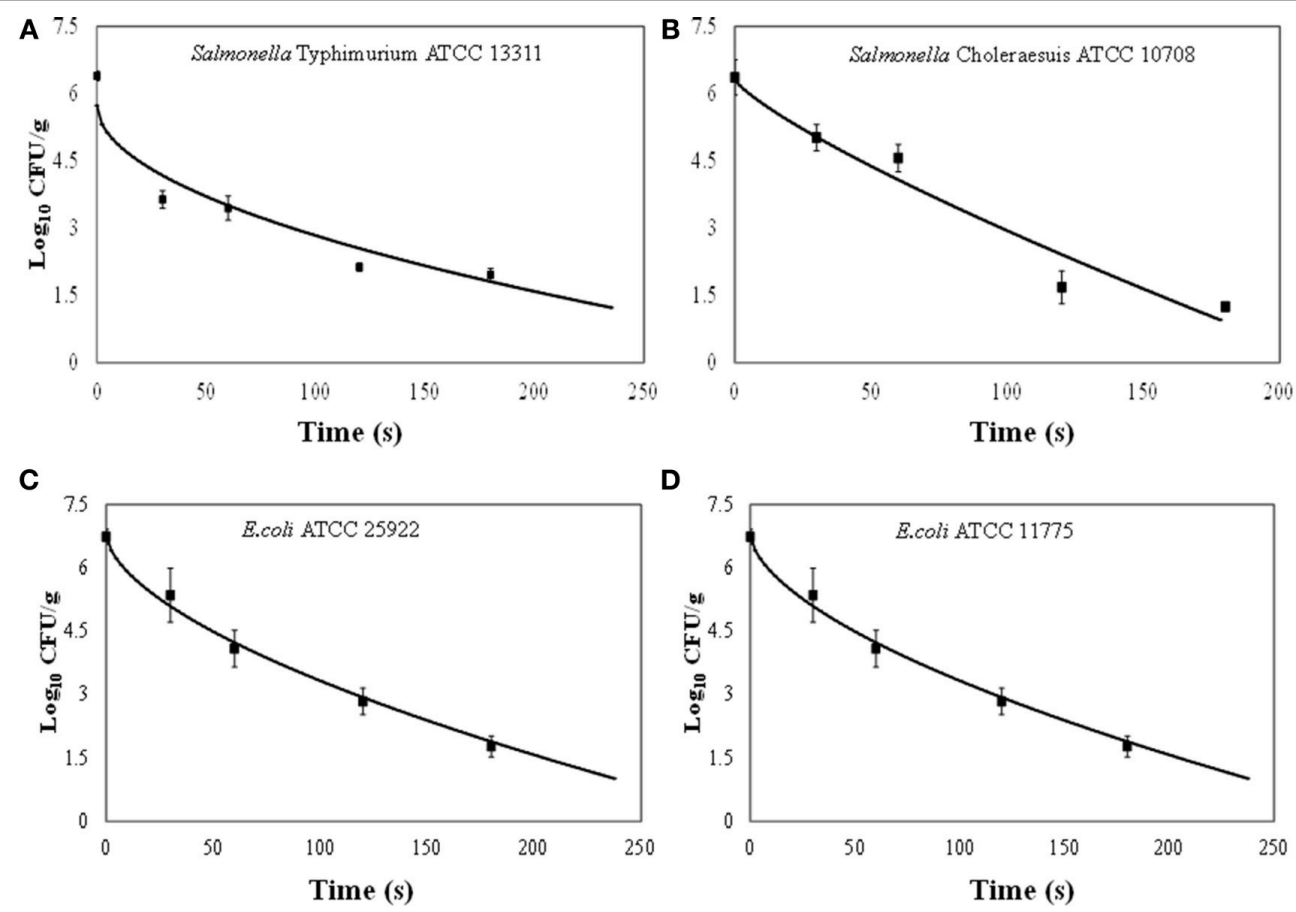

D

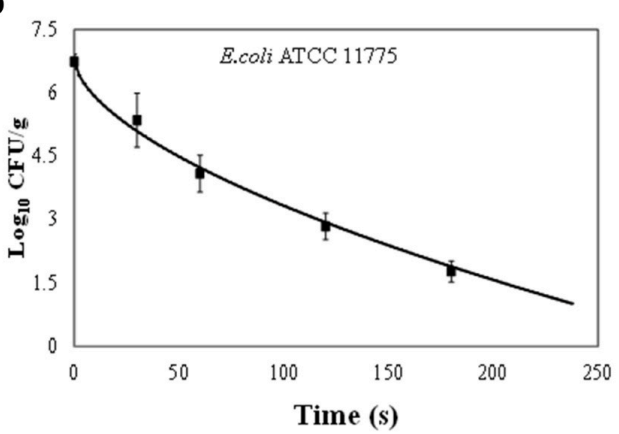

FIGURE 3 | Effect of treatment time on the inactivation of Salmonella Typhimurium, ATCC 13311 (A), Salmonella Choleraesuis, ATCC 10708 (B), Escherichia coli ATCC 25922 (C), Escherichia coli ATCC 11775 (D) on apples by the atmospheric cold plasma treatment using air as the plasma-forming gas. Error bars denote standard deviations. 
were analyzed in the Weibull frequency distribution model. We used an independent set of data to validate the models. Consequently, based on the validation statistics obtained from using an independent set of experimental data, the predictive results from the above model can be considered accurate. $P$ values $>0.05$ were considered statistically significant.

Our results showed that both the plasma exposure time as well as the fixed gas composition played a key role regarding the inactivation of E. coli and Salmonella on apples. Showing dependence on the plasma exposure time, downward concave survival curves were observed. The parameters for Weibull models are shown in Table 1. The goodness-of-fit of the inactivation models was compared by determining the $R^{2}$ values. The goodness-of-fit of the models is described by the root mean square error (RMSE), which was between 0.17 and 0.53 and which thus proved the suitability of the Weibull model.

\section{RESULTS AND DISCUSSION}

\section{Inactivation of Bacteria on Golden Delicious Apples}

The schematic view of the ACP unit is shown in Figure 1. Emission spectra from the plasma discharge is shown in Figure 2. It is quite evident from the spectra (Figure 2), the major emission lines were in the $300-450 \mathrm{~nm}$ regions and attributed to nitrogen species. These bands are associated with the transition from the second positive system of $\mathrm{N}_{2}$, the first negative system of $\mathrm{N}_{2}^{+}$and the beta and gammas system of NO. Moreover, the lines between 315 and $405 \mathrm{~nm}$ are linked to the second positive system of $\mathrm{N}_{2}$ whilst the bands approximately at 391 and $426.5 \mathrm{~nm}$ are due to the first negative system of $\mathrm{N}_{2}^{+}$(41). It was observed that a strong emission peak in the UV range was also observed which could be attributed to UV photons in the germicidal range.

The influence of ACP treatments on viability of Salmonella and E. coli was investigated in our study. Atmospheric plasma, a non-thermal surface decontamination technique is capable of generating various groups of antimicrobial agents which includes photons, electrons, positively and negatively charged ions, atoms, free radicals and excited or non-excited molecules $(42,43)$. In our study, plasma discharge consisted of nitrogen species and UV photons as illustrated in Figure 2.

The initial concentration $\left(\mathrm{N}_{0}\right)$ of Salmonella or E. coli cells on each apple was approximately $10^{7} \mathrm{CFU} / \mathrm{cm}^{2}$. Survival curves showed non-linear inactivation kinetics (Figures 3A,B). Generally, the reductions for both E. coli strains were not significantly different at the same exposure time intervals. E. coli populations were reduced by $>1 \log$ after $60 \mathrm{~s}$. The concentration of E. coli significantly decreased $(>5.0 \log )$ at 180 and 240 s. E.

TABLE 2 | Treatment time required for 5 log reduction (99.999\%) in bacterial population.

$\begin{array}{ll}\text { Microbe } & t_{5 d}(s)\end{array}$

Salmonella Typhimurium ATCC 13311

Salmonella Choleraesuis ATCC $10708 \quad 163.39$

Escherichia coli ATCC $25922 \quad 186.20$

Escherichia coli ATCC $11775 \quad 178.22$

Data reported as means.
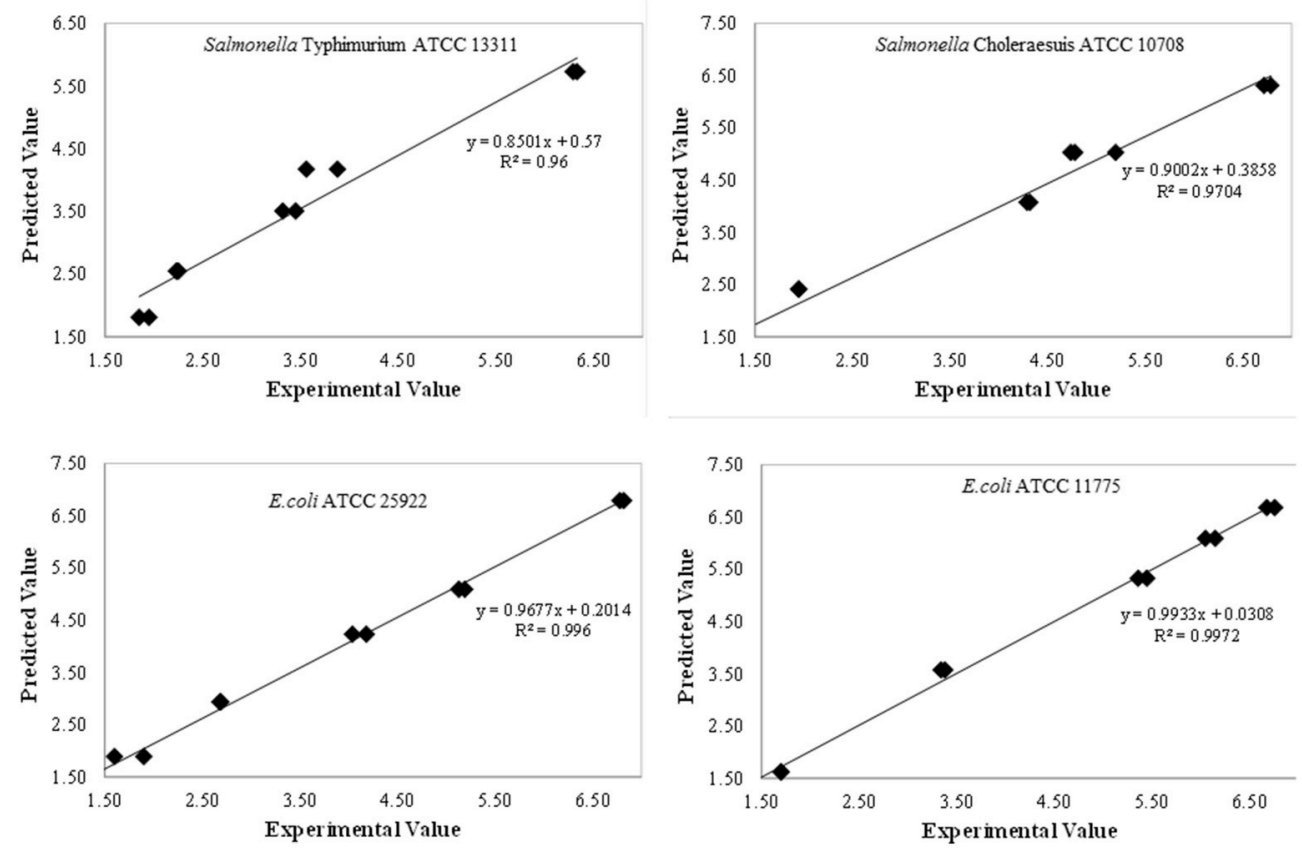

FIGURE 4 | Model predictions and model efficacy. 
TABLE 3 | Average mean deviation for Salmonella strains.

\begin{tabular}{|c|c|c|}
\hline Experimental & Predicted & Error (\%) \\
\hline \multicolumn{3}{|c|}{ Salmonella typhimurium } \\
\hline 6.68 & 6.68 & 0.01 \\
\hline 6.76 & 6.68 & 0.38 \\
\hline 6.05 & 6.09 & 0.25 \\
\hline 6.15 & 6.09 & 0.30 \\
\hline 5.36 & 5.33 & 0.18 \\
\hline 5.45 & 5.33 & 0.73 \\
\hline 3.38 & 3.57 & 1.91 \\
\hline 3.34 & 3.57 & 2.33 \\
\hline 1.70 & 1.62 & 1.53 \\
\hline 1.70 & 1.62 & 1.53 \\
\hline 1.00 & 0.98 & 0.62 \\
\hline \multicolumn{3}{|c|}{ Salmonella choleraesuis 10708} \\
\hline 6.79 & 6.31 & 2.34 \\
\hline 6.72 & 6.31 & 2.01 \\
\hline 4.78 & 5.03 & 1.76 \\
\hline 4.74 & 5.03 & 2.05 \\
\hline 5.20 & 5.03 & 1.08 \\
\hline 4.29 & 4.08 & 1.65 \\
\hline 4.32 & 4.08 & 1.87 \\
\hline 1.95 & 2.41 & 7.89 \\
\hline 1.95 & 2.41 & 7.89 \\
\hline 1.20 & 0.91 & 8.06 \\
\hline 1.20 & 0.91 & 8.06 \\
\hline
\end{tabular}

coli ATCC 25922 and E. coli ATCC 11775 reductions ranged from 1.4 to 5.3 and 0.6 to $5.5 \log _{10} \mathrm{CFU} / \mathrm{cm}^{2}$, respectively. The ACP inactivation of E. coli ATCC 25922 and E. coli ATCC 11775 on apples is presented in Figures 3C,D). Our results are in agreement of previous studies that demonstrated antimicrobial efficiency of cold plasma treatment on E. coli cells on apples. In an earlier study, E. coli O157:H7 populations on Golden Delicious apples were reduced by 3.5 and $3.0 \log _{10} \mathrm{CFU} / \mathrm{cm}^{2}$, respectively after $180 \mathrm{~s}$ exposure at a flow rates of 30 or $40 \mathrm{ml} / \mathrm{min}$ (29). The application of one atmosphere uniform glow discharge plasma system (OAUGDP) has been reported to reduce E. coli O157:H7 on Red Delicious apples by $3 \log _{10} \mathrm{CFU} / \mathrm{cm} 2$ after $120 \mathrm{~s}$ exposure (27). Ziuzina et al. (35) demonstrated that ACP reduced E. coli on strawberries by 1.2 and $1.6 \log _{10} \mathrm{CFU} /$ sample after $60 \mathrm{~s}$ and $120 \mathrm{~s}$ exposure, respectively, with significantly different reductions of $3.5 \log _{10} \mathrm{CFU} / \mathrm{cm}^{2}$ after treatment for $300 \mathrm{~s}(p<$ $0.05)$. Recent studies have shown that plasma is a source of heat, UV irradiation, charged particles, reactive oxygen, and nitrogen based species (ROS and RNS, respectively) with a main role given to the species as disinfectants (20-23, 44-47). Our findings clearly demonstrated that increasing the treatment time caused an increased antimicrobial efficacy of ACP against the two strains of E. coli.

Inactivation of Salmonella Typhimurium and Salmonella Choleraesuis on apples is presented in Figures 3A,B. Inactivation of Salmonella strains showed a time-dependent reduction for all treatments. Salmonella Typhimurium and Salmonella
TABLE 4 | Average mean deviation for E.coli strains.

\begin{tabular}{|c|c|c|}
\hline Experimental & Predicted & Error (\%) \\
\hline \multicolumn{3}{|c|}{ Escherichia coli ATCC 25922} \\
\hline 6.54 & 6.79 & 1.28 \\
\hline 6.94 & 6.79 & 0.71 \\
\hline 4.78 & 5.09 & 2.19 \\
\hline 4.58 & 4.23 & 2.53 \\
\hline 4.04 & 4.23 & 1.59 \\
\hline 3.15 & 2.94 & 2.27 \\
\hline 2.69 & 2.94 & 3.04 \\
\hline 1.60 & 1.89 & 6.05 \\
\hline 1.60 & 1.89 & 6.05 \\
\hline 1.00 & 0.98 & 0.62 \\
\hline 1.00 & 0.98 & 0.62 \\
\hline \multicolumn{3}{|c|}{ Escherichia coli ATCC 11775} \\
\hline 6.39 & 6.68 & 1.52 \\
\hline 6.68 & 6.68 & 0.01 \\
\hline 6.05 & 6.09 & 0.25 \\
\hline 6.16 & 6.09 & 0.35 \\
\hline 5.20 & 5.33 & 0.84 \\
\hline 5.45 & 5.33 & 0.73 \\
\hline 3.38 & 3.57 & 1.91 \\
\hline 3.38 & 3.57 & 1.91 \\
\hline 3.76 & 3.57 & 1.65 \\
\hline 1.60 & 1.62 & 0.46 \\
\hline 1.70 & 1.62 & 1.53 \\
\hline
\end{tabular}

Choleraesuis reductions ranged from 2.8 to 4.8 and 1.3 to 5.3 $\log _{10} \mathrm{CFU} / \mathrm{cm}^{2}$, respectively. Generally, Salmonella inactivation followed the same trend as for E. coli where reductions for both strains were not significantly $(p<0.05)$ different at the same exposure time intervals. After $30 \mathrm{~s}$ and $60 \mathrm{~s}$ exposure, Salmonella populations were reduced by $>1 \log$. At higher treatment times (180-240s), Salmonella Typhimurium and Salmonella Choleraesuis were reduced to 4.4 to $5.3 \log _{10} \mathrm{CFU} / \mathrm{cm}^{2}$, respectively. Salmonella Typhimurium was slightly resistant to plasma as compared to other E.Coli and other Salmonella strain. The detection limit in the current study was $2 \log _{10}$ CFU/apple piece.

Our findings suggest that Salmonella populations decreased as the treatment time increased. The relationship between the level of microbial log reduction and treatment time was observed to be non-linear (Figures 3A,B). Our results are in agreement of previous studies that demonstrated antimicrobial efficiency of cold plasma treatment on E. coli and Salmonella on apples. In an earlier study, Salmonella populations on Golden Delicious apples were reduced by 3.5 and $3.0 \log _{10} \mathrm{CFU} / \mathrm{cm}^{2}$, respectively, after $180 \mathrm{~s}$ exopause at flow rates of 30 or $40 \mathrm{ml} / \mathrm{min}$ (29). The application of one atmosphere uniform glow discharge plasma system (OAUGDP) has been reported to reduce Salmonella on Red Delicious apples by $3 \log _{10} \mathrm{CFU} / \mathrm{cm}^{2}$ after $120 \mathrm{~s}$ exposure (27). In the same study, correspondingly Salmonella reductions were 1.7 and $3.8 \log _{10} \mathrm{CFU} /$ sample after exposure for 120 and 300 s, respectively. Reduction of E. coli O157:H7, Salmonella, 
and $L$. monocytogenes have also been reported for apples and lettuce using gas plasma technology (48). Possible mechanism of inactivation may be reactive species produced in plasma which react with the amino-acid in proteins and further cause structural changes in proteins and results in destruction of the vegetative cells (49). In addition, $\mathrm{OH}, \mathrm{O}$, and $\mathrm{O}_{3}$ could break structural bonds in cell wall component pedtidoglycan, like C$\mathrm{O}, \mathrm{C}-\mathrm{N}$ bonds, leading to cell wall destruction (50) and cell death. Salmonella and E. coli are Gram negative bacteria with a thinner outer membrane compared to the Gram positive $L$. monocytogenes. Clearly, the cell characteristics are critical factors for inactivation efficacy, but no clear trend is apparent from this study and highly complex interactions with the system, process, surface or medium may also impact on efficacy in combination with cell type.

\section{Modeling Inactivation Kinetics}

Analysis of kinetics data showed that Weibull model was a good fit for the experimental data obtained (Table 1). Both bacteria studied were susceptible to plasma treatment, but experimental inactivation data and predicted parameters indicated that Salmonella Typhimurium ATCC 13311 was most resistant to plasma treatment than other microbes. It was observed that for $5 \log$ reduction of Salmonella Typhimurium, a treatment time of $288.14 \mathrm{~s}$ is required. In contrast, Salmonella Choleraesuis required a treatment time of $163.39 \mathrm{~s}$ for $99.999 \%$ reduction.

Relative changes in bacterial concentration as a function of treatment time were fitted to Weibull model $(P<0.05)$ with coefficients of determination (Table 1) and a low RMSE. The $R^{2}$ values of 0.92 and above (Table 1) show that the Weibull model was a good fit for the experimental data analyzed. $P$ values $>1$ indicate the susceptibility of the remaining cells to the treatment. The parameter estimates were reported in terms of a rate constant. The $t_{5 d}\left(t_{5 d}\right.$-the time required for a $5 \log _{10}$ reduction) for both E. coli and Salmonella strains is shown in Table 2. The treatment time varied between 288.14 and $163.39 \mathrm{~s}$. Salmonella Typhimurium was the most resistant bacteria.

The developed models for inactivation curves of pathogens describing the effect of plasma treatment on log reduction were validated using predictive modeling parameters. Independent set of experiments were conducted to validate the developed models. Predicted values of log reduction obtained using model equations were in good agreement with the experimental values. The experimental and predicted values were closely correlated with the experimental data as demonstrated by regression coefficient $\left(\mathrm{R}^{2}\right)$ as shown in Figure 4. To confirm the adequacy of the fitted models, studentised residuals vs. run order were tested and the residuals were observed to be scattered randomly, suggesting that

\section{REFERENCES}

1. Stefano P, Gilbert S, Kong MG. Cold atmospheric plasma disinfection of cut fruit surfaces contaminated with migrating microorganisms. J Food Prot. (2008) 71:1619-25. doi: 10.4315/0362-028X-71.8.1619

2. Olaimat AN, Holley RA. Factors influencing the microbial safety of fresh produce: a review. Food Microbiol. (2012) 32:1-19. doi: 10.1016/j.fm.2012.04.016 the variance of the original observations were constant for all responses. Further, the normality assumption was satisfied as the residual plot approximated to a straight line for all responses.

The average mean deviation (E) and multiple correlation coefficients $\left(\mathrm{R}^{2}\right)$ were used to determine the fitting accuracy of data (51).

$$
E(\%)=\frac{1}{n_{e}} \sum_{i=1}^{n}\left\|\frac{V_{E}-V_{p}}{V_{E}}\right\| \times 100
$$

where, $n_{e}$ is the number of experimental data, $V_{E}$ is the experimental value and $V_{P}$ is the predicted value.

The variation between the predicted and experimental log reduction values obtained for E. coli and Salmonella strains were within acceptable error range as depicted by average mean deviation $(\mathrm{E} \%)$; therefore, the predictive performance of the established model may be considered acceptable (Tables 3, 4). It is indicated from the table that predicted values were in close agreement with the experimental values. The predicted values were found to be within the range of experimental values and were not significant at $p<0.05$ using paired $t$-test.

\section{CONCLUSIONS}

Our results indicate that atmospheric cold plasma inactivated $E$. coli and Salmonella strains on the surface of Golden Delicious apples. Inactivation times for $\mathrm{a} \approx 5 \log$ cycle reduction ranged between 120 and $240 \mathrm{~s}$. The inactivation depended significantly on treatment time and was well explained by the Weibull model. The results presented in the current study demonstrate the efficacy of ACP in activation of E. coli and Salmonella strains on apples. Overall, our results demonstrated the potential of atmospheric cold plasma as a means of improving the microbiological safety of fruits. Future studies are needed to address the feasibility for scale-up of this technology to pilot and commercial scales for decontamination pathogenic bacteria on fresh produce.

\section{AUTHOR CONTRIBUTIONS}

AK-N conducted the experiments and evaluated the results. SL conducted the experiments. AP conducted the kinetic modeling. SY validated and optimized the gas plasma system.

\section{FUNDING}

USDA/NIFA Grant No. 2015-38821-24343.
3. Zheng L, Bae YM, Jung KS, Heu S, Lee SY. Antimicrobial activity of natural antimicrobial substances against spoilage bacteria isolated from fresh produce. Food Control (2013) 32:665-72. doi: 10.1016/j.foodcont.2013. 01.009

4. Yeni F, Acar S, Polat öG, Soyer Y, Alpas H. Rapid and standardized methods for detection of foodborne pathogens and mycotoxins on fresh produce. Food Control. (2014) 40:359-67. doi: 10.1016/j.foodcont.2013. 12.020 
5. Centers for Disease and Prevention (CDC) (2013). Foodborne Outbreak Online Database (FOOD). Available online at: http://wwwn.cdc.gov/ foodborneoutbreaks/ (Accessed 16 March, 2018).

6. Painter JA, Hoekstra RM, Ayers T, Tauxe RV, Braden CR, Angulo FJ, et al. Attribution of foodborne illnesses, hospitalizations, and deaths to food commodities by using outbreak data, United States, 1998-2008. Emerging Infect Dis. (2013) 19:407-15. doi: 10.3201/eid1903.111866

7. Song HP, Kim B, Choe JH, Jung S, Moon SY, Choe W, et al. Evaluation of atmospheric pressure plasma to improve the safety of sliced cheese and ham inoculated by 3 -strain cocktail Listeria monocytogenes. Food Microbiol. (2009) 26:432-6. doi: 10.1016/j.fm.2009.02.010

8. Kim B, Yun H, Jung S, Jung Y, Jung H, Choe W, et al. Effect of atmospheric pressure plasma on inactivation of pathogens inoculated onto bacon using two different gas compositions. Food Microbiol. (2011) 28:9-13. doi: 10.1016/j.fm.2010.07.022

9. Harris LJ, Farber LR, Beuchat ME, Parish TV, Suslow EH, Garrett FF, et al. Outbreaks associated with fresh produce: incidence, growth, and survival of pathogens in fresh and fresh-cut produce. Compr Rev Food Sci Food Safety (2003) 2:78-86. doi: 10.1111/j.1541-4337.2003.tb00031.x

10. Sivapalasingam S, Friedman CR, Cohen L, Tauxe R. Fresh produce: a and growing cause of outbreaks of foodborne illness in the United States, 1973 through 1997. J Food Prot. (2004) 67:2342-53.

11. Callejón RM, Rodriguez-Naranjo MI, Ubeda C, Hornedo-Ortega R, GarciaParrilla MC, Troncoso, AM. Reported Foodborne Outbreaks Due to Fresh Produce in the United States and European Union: Trends and Causes. Foodborne Pathog Dis. (2015) 12:32-8. doi: 10.1089/fpd.2014.1821

12. Lynch M, Tauxe R, Hedberg C. The growing burden of foodborne outbreaks due to contaminated fresh produce: risks and opportunities. Epidemiol Infect. (2009) 137:307-15. doi: 10.1017/S0950268808001969

13. Tiwari BK, O'Donnell CP, Cullen PJ. Effect of non-thermal processing technologies on the anthocyanin content of fruit juices. Food Sci Technol. (2009) 20:137-45. doi: 10.1016/j.tifs.2009.01.058

14. Mandal R, Singh A, Anubhav Pratap SA. Recent developments in cold plasma decontamination technology in the food industry. Trends Food Sci Technol. (2018) 80:93-103. doi: 10.1016/j.tifs.2018.07.014

15. Millan-Sango D, Han L, Milosavljevic V, Van, Impe JF, Bourke P, Cullen PJ, et al. (2015). Assessing bacterial recovery and efficacy of cold at mospheric plasma treatments. Food Bioprod Process 6:154-60. doi: 10.1016/j.fbp.2015.07.011

16. Baier M, Foerster J, Schabel U, Knorr D, Herppich WB, Schlüter O. Direct non-thermal plasma treatment for the sanitation of fresh corn salad leaves: evaluation of physical and physiological effects and antimicrobial efficacy. Postharvest Bio Tech. (2013) 84:81-7. doi: 10.1016/j.postharvbio.2013.03.022

17. Deng S, Ruan R, Mok CK, Huang G, Lin X, Chen P. Inactivation of Escherichia coli on almonds using nonthermal plasma. J Food Sci. (2007) 72:M62-6. doi: 10.1111/j.1750-3841.2007.00275.x

18. Ragni BA, Iaccheri E, Gozzi G, Cevoli C, Vannini L. Influence of the electrode material on the decontamination efficacy of dielectric barrier discharge gas plasma treatments towards Listeria monocytogenes and Escherichia coli. Inn Food Sci and Emg Tech. (2016) 37:170-6. doi: 10.1016/j.ifset.2016.07.029

19. El-Sayed WS, Ouf SA, Mohamed AA. Deterioration to extinction of wastewater bacteria by non-thermal atmospheric pressure air plasma as assessed by $16 \mathrm{~S}$ rDNA-DGGE fingerprinting. Front Microbiol. (2015) 6:1098. doi: 10.3389/fmicb.2015.01098

20. Niemira BA, Boyd G, Sites J. Cold plasma rapid decontamination of food contact surfaces contaminated with Salmonella biofilms. J Food Sci. (2014) 79:917-22. doi: 10.1111/1750-3841.12379

21. Niemira BA, Boyd G, Sites J. Cold plasma inactivation of Escherichia coli O157:H7 biofilms. Front Sustain Food Syst. (2018) 2:47. doi: 10.3389/fsufs.2018.00047

22. Fernandez A, Noriega E, Thompson A. Inactivation of Salmonella enterica serovar Typhimurium on fresh produce by cold atmospheric gas plasma technology. Food Microbiol. (2013) 33:24-9. doi: 10.1016/j.fm. 2012.08.007

23. Timmons C, Pai K, Jacob J, Zhang G, Ma LM. Inactivation of Salmonella enterica, Shiga toxin-producing Escherichia coli, and Listeria monocytogenes by a novel surface discharge cold plasma design. Food Control (2017) 84:45562. doi: 10.1016/j.foodcont.2017.09.007
24. Moisan M, Barbeau J, Crevier MC, Pelletier J, Philip N, Saoudi B. Plasma sterilization: methods and mechanisms. Pure Appl Chem. (2002) 74:349-58. doi: 10.1351/pac200274030349

25. Laroussi M. Low temperature plasma-based sterilization: overview and state-of-the-art. Plasma Process Polym. (2005) 2:391-400. doi: $10.1002 /$ ppap.200400078

26. Deng XT, Shi JJ, Kong MG. Physical mechanisms of inactivation of Bacillus subtilis spores using cold atmospheric plasmas. IEEE Trans Plasma Sci. (2006) 34:1310-6. doi: 10.1109/TPS.2006.877739

27. Critzer FJ, Kelly-Wintenberg K, South SL, Golden DA. Atmospheric plasma inactivation of foodborne pathogens on fresh produce surfaces. J Food Prot. (2007) 70:2290-6. doi: 10.4315/0362-028X-70.10.2290

28. Kayes MM, Critzer FJ, Kelly-Wintenberg K, Roth JR, Montie TC, Golden DA. Inactivation of foodborne pathogens using a one atmosphere uniform glow discharge plasma. Foodborne Pathog Dis. (2007) 4:50-9. doi: $10.1089 /$ fpd.2006.62

29. Niemira BA, Sites J. Cold plasma inactivates Salmonella stanley and Escherichia coli O157:H7 inoculated on golden delicious apples. J Food Prot. (2008) 71:1357-65. doi: 10.4315/0362-028X-71.7.1357

30. Misra NN, Keener KM, Bourke P, Mosnier JP, Cullen PJ. In-package atmospheric pressure cold plasma treatment of cherry tomatoes. J Biosci Bioeng. (2014) 118:177-82. doi: 10.1016/j.jbiosc.2014.02.005

31. Batz MB, Hoffmann S, Morris JG Jr. Ranking the disease burden of 14 pathogens in food sources in the United States using attribution data from outbreak investigations and expert elicitation. J Food Prot. (2012) 75:1278-91. doi: 10.4315/0362-028X.JFP-11-418

32. Bourke P, Ziuzina D, Han L, Cullen PJ, Gilmore BF. Microbiological interactions with cold plasma. J Appl Microbiol. (2017) 123:308-24. doi: $10.1111 /$ jam. 13429

33. Lee H, EunKim J, Chung M-S, Min SC. Cold plasma treatment for the microbiological safety of cabbage, lettuce, and dried figs. Food Microbiol. (2015) 51:74-80. doi: 10.1016/j.fm.2015.05.004

34. Fernandez A, Shearer N, Wilson A, Thompson A. Effect of microbial loading on the efficiency of cold atmospheric gas plasma inactivation of Salmonella enterica serovar Typhimurium. Int J Food Microbiol. (2012) 3:17580. doi: 10.1016/j.ijfoodmicro.2011.02.038

35. Ziuzina D, Patil S, Cullen PJ, Keener KM, Bourke P. Atmospheric Cold Plasma inactivation of Escherichia coli, Salmonella enterica serovar Typhimurium and Listeria monocytogenes inoculated on fresh produce. Food Microbiol. (2014) 42:109-16. doi: 10.1016/j.fm.2014.02.007

36. Geeraerd AH, Valdramidis VP, Van Impe JF. GInaFiT, A freeware tool to assess non-log-linear microbialsurvivor curves. Int J Food Microbiol. (2005) 102:95-105. doi: 10.1016/j.ijfoodmicro.2004.11.038

37. Corradini MG, Normand MD, Peleg M. Modeling non-isothermal heat inactivation of microorganisms having biphasic isothermal survival curves. Int J Food Microbiol. (2007) 116:391-9. doi: 10.1016/j.ijfoodmicro.2007.02.004

38. Corradini MG, Peleg M. A model of microbial survival curves in water treated with a volatile disinfectant. J Appl Microbiol. (2003) 95:1268-76. doi: 10.1046/j.1365-2672.2003.02104.x

39. Hajmeer M, Basheer I, Hew C, Cliver DO. Modeling the survival of Salmonella spp. in chorizos. Int J Food Microbiol. (2006) 107:59-67. doi: 10.1016/j.ijfoodmicro.2005.08.012

40. Van Boekel MAJS. On the use of the Weibull model to describe thermal inactivation of microbial vegetative cells. Int J Food Microbiol. (2002) 74:13959. doi: 10.1016/S0168-1605(01)00742-5

41. Connolly J, Valdramidis V, Byrne E, Karatzas K, Cullen P, Keener KM, et al. Characterization and antimicrobial efficacy against E. coli of a helium/air plasma at atmospheric pressure created in a plastic package. J Phys D Appl Phys. (2013) 46:035401. doi: 10.1088/0022-3727/46/3/035401

42. Moreau M, Orange N, Feuilloley MGJ. Non-thermal plasma technologies: new tools for bio-decontamination. Biotechnol Adv. (2008) 26:610-7. doi: 10.1016/j.biotechadv.2008.08.001

43. Ekezie FC, Sun DW, Han Z, Cheng JH. Microwave-assisted food processing technologies for enhancing product quality and process efficiency: a review of recent developments. Trends Food Sci Technol. (2017) 67:58-69. doi: 10.1016/j.tifs.2017.05.014

44. Laroussi M, Leipold F. Evaluation of the roles of reactive species, heat, and, U. V radiation in the inactivation of bacterial cells by air 
plasmas at atmospheric pressure. Int J Mass Spectrom. (2004) 233:81-6. doi: 10.1016/j.ijms.2003.11.016

45. Laroussi M. Low-temperature plasmas for medicine? Plasma Sci IEEE Trans Plasma Sci. (2009) 37:714-25. doi: 10.1109/TPS.2009. 2017267

46. Pankaj SK, Misra NN, Cullen PJ. Kinetics of tomato peroxidase inactivation by atmospheric pressure cold plasma based on dielectric barrier discharge. Innov Food Sci Emerg Technol. (2013) 19:153-7. doi: 10.1016/j.ifset. 2013.03.001

47. Mishra R, Bhatia S, Pal R, Visen A, Trivedi H. Cold plasma: emerging as the new standard in food safety. Res Inv Int J Eng Sci. (2016) 6:15-20.

48. Misra NN, Tiwari BK, Raghavarao KSMS, Cullen PJ. Nonthermal plasma inactivation of food-borne pathogens. Food Eng Res. (2011) 3:159-70. doi: 10.1007/s12393-011-9041-9

49. Surowsky B, Fröhling A, Gottschalk N, Schlüter O, Knorr D. Impact of cold plasma on Citrobacter freundii in apple juice: inactivation kinetics and mechanisms. Int J Food Microbiol. (2014) 174:63-71. doi: 10.1016/j.ijfoodmicro.2013.12.031
50. Misra NN, Schlüter O, Cullen PJ. Cold Plasma in Food and Agriculture: Fundamentals and Applications. 1st ed. San Diego, CA: Academic Press, Elsevier Ltd. (2016).

51. Tiwari BK, Muthukumarappan K, O’Donnell CP, Cullen PJ. Modelling color degradation of orange juice by ozone treatment using response surface methodology. J Food Eng. (2008) 88:553-60. doi: 10.1016/j.jfoodeng.2008.03.021

Conflict of Interest Statement: The authors declare that the research was conducted in the absence of any commercial or financial relationships that could be construed as a potential conflict of interest.

Copyright (c) 2018 Kilonzo-Nthenge, Liu, Yannam and Patras. This is an open-access article distributed under the terms of the Creative Commons Attribution License (CC $B Y)$. The use, distribution or reproduction in other forums is permitted, provided the original author(s) and the copyright owner(s) are credited and that the original publication in this journal is cited, in accordance with accepted academic practice. No use, distribution or reproduction is permitted which does not comply with these terms. 